\title{
Farklı orijinli kızılçam (Pinus brutia Ten.) fidanlarının morfolojik özelliklerinin karşılaştırılması
}

\section{Comparison of seedling morphological characteristics in brutian pine (Pinus brutia Ten.) provenances}

\author{
Mahmut ÇERÇioĞLU1 1 , Durmuş ÇETINKAYA²
}

${ }_{1}^{1 B u r d u r}$ Mehmet Akif Ersoy Üniversitesi, Gölhisar Meslek Yüksekokulu, Ormancılık Bölümü, Gölhisar, Burdur ${ }^{2}$ Çukurova Üniversitesi, Aladağ Meslek Yüksekokulu, Ormancılık Bölümü, Aladağ, Adana

\section{Eser Bilgisi / Article Info}

Araştırma makalesi / Research article DOI: 10.17475/ artvinofd.856855

Sorumlu yazar / Corresponding author Mahmut ÇERÇioĞLU

e-mail: cercioglumahmut@gmail.com

Geliş tarihi / Received

08.01.2021

Düzeltme tarihi / Received in revised form

04.02.2021

Kabul Tarihi / Accepted

05.02.2021

Elektronik erişim / Online available 12.05.2021

\begin{tabular}{l}
\hline Anahtar kelimeler: \\
Kızılçam \\
Fidan \\
Morfoloji \\
Orijin \\
Varyasyon \\
\hline
\end{tabular}

Keywords:

Brutian pine

Seedling

Morphology

Origin

Variation

\begin{abstract}
Özet
Çalışma, Burdur-Gölhisar orman fidanlığında yetiştirilen, Bucak (Uludere) orijinli Döşemealtı tohum bahçesi (TB19) (P2) ve Gölhisar (Evciler-Koçaş) orijinli Düzlerçamı tohum bahçesi (TB8)(P1)'nden elde edilen tohumlardan gelen kızılçam fidanları üzerinde gerçekleştirilmiştir. Farklı orijinli ve 1+0 yaşlı kızılçam (Pinus brutia Ten.) fidanları, aynı yetişme ortamında bazı morfolojik özellikler (fidan boyu, kök boğazı çapı, en uzun kök uzunluğu, yan dal, tomurcuk, kök ve ibre sayıları) bakımından karşılaştırılmıştır. Varyans analizi sonuçlarına göre, popülasyonlar fidan boyu ve kök boğazı çapı bakımından benzerlik ( $p>0.05$ ) gösterirken, kök ve tomurcuk sayısı bakımından popülasyonlar arası anlamlı $(p<0.05)$ farklılıklar tespit edilmiştir. Uygulanan korelasyon analizi sonucunda morfolojik özellikler bakımından genel olarak anlamlı $(p<0.05)$ pozitif ilişkiler ortaya çıkmıştır. Ayrıca, hesaplanan gürbüzlük indisi bakımından en etkili olan faktörler sırasıyla en uzun kökün uzunluğu ve tomurcuk sayısı olarak bulunmuştur. Türk Standartları Enstitüsü (TSE) fidan kalite sınıfları bakımından P1 popülasyonuna ait fidanların $\% 56$ 'sı 1 1. sınıf, \%22'si 2 2. sınıf, $\% 22$ 'si dikime elverişsizdir. P2 popülasyonunda ise fidanların $\% 84^{\prime}$ ü 1 . sınıf, $\% 10^{\prime} u$ 2. sınıf, $\% 6^{\prime}$ sı dikime elverişsiz olarak belirlenmiştir. Elde edilen sonuçlar ışığında, Bucak (Uludere) orijinli fidanların gerek morfolojik özellikler gerekse de TSE fidan kalitesi bakımından daha yüksek değerlere sahip olduğu ortaya çıkmıştır.
\end{abstract}

\begin{abstract}
The study was carried out on Brutian Pine (Pinus brutia Ten.) seedlings from the seeds originated from Dosemealti seed orchard (TB19) (P2) established by Bucak (Uludere) provenance and Duzlercami seed orchard (TB8)(P1) established by Golhisar (Evciler-Kocas) provenance, grown in Burdur-Gölhisar forest nursery. The seedling of the orchards of the species were sampled at $1+0$ year to compare in terms of some morphological characteristics (seedling height, root collar diameter, root length, side branch, bud, root and needle numbers) at the nursery. According to the results of the variance analysis the seed orchard populations were statistically similar $(p>0.05)$ in terms of seedling length and root collar diameter, while the populations had significant differences $(p<0.05)$ in terms of root and bud numbers. As a result of the correlation analysis, generally significant $(p<0.05)$ positive relationships in terms of morphological features were determined. In addition, the sturdiness index of the seedlings was calculated in the light of the measurements obtained. The most effective factors in the context of the sturdiness index were the length of the longest root and the number of buds, respectively. In terms of seedling quality classes of the Turkish Standards Institute (TSE), 56\%of the seedlings were 1st class, $22 \%$ were 2 nd class, $22 \%$ were unsuitable for planting in P1. In the P2 population, $84 \%$ of the seedlings were 1 st class, $10 \% 2$ nd class, $6 \%$ unsuitable for planting. As a result, it was determined that the seedlings originated from Bucak (Uludere) showed higher growth performance in terms of both morphological characteristics and TSE seedling quality than Golhisar.
\end{abstract}

\section{Giriş}

İnsanoğlu ormanlardan geçmişten günümüze kadar çeşitli amaçlarla faydalanmıştır ve faydalanmaktadır. Bu faydalanmanın geçmişte sistematik olarak gerçekleştirilmemesi nedeniyle ormanlar büyük bir tahribata uğratıımıştır. Ormancılık bilim dalının ortaya çıkışıyla beraber biyosferin en önemli bileşenlerinden birisi olan ormanlardan sürdürülebilir bir şekilde faydalanmak için sistemler geliştirilmiştir. Zira, biyotik ve abiyotik zararlılara karşı dayanıklı, morfolojik bakımdan yüksek gelişim gösteren fidanlar gerek ağaçlandırma ve rehabilitasyon gibi ormancılık uygulamalarında ve gerekse de orman ıslahı çalışmalarında önemli bir hale gelmiştir. Çünkü kaliteli fidanlarla tesis edilecek olan ormanlar karlı işletmecilik için ilk aşamalardan biridir. 
Kaliteli bir fidanın yetiştirilmesi için hiç şüphesiz bitkinin iç ve dış yapısının iyi tanınması gerekir (Toker 2004). Yapılan çalışmalarda fidan tipinin ve morfolojik özelliklerin ağaçlandırmalar noktasında büyük öneme sahip olduğu belirtilmiştir (Bilir ve ark. 2010, Gülcü ve Uysal 2010, Şevik ve ark. 2013, Özel ve ark. 2018, Bilir 2019, Çetinkaya ve Bilir 2019, Gülseven ve ark. 2019, Uslu ve Bilir 2020). Örneğin boylu ve kalın çaplı fidanların ağaçlandırma çalışmalarında yaşama yüzdesi ve gelişim bakımından diğerlerine göre üstünlük gösterdiği belirlenmiştir (Bacon 1979, Rose ve ark. 1990, Yahyaoğlu ve Genç 2007, Gülcü ve Uysal 2010).

Araştırmaya konu kızılçam (Pinus brutia Ten.) dünyada başta Türkiye olmak üzere İtalya, Güney Ege Adaları, Kıbrıs, Lübnan, Ürdün Irak, Suriye, Kırım ve Batı Kafkasya'da yayılış yapmaktadır (Selik 1963, Davis 1965, Critchfield ve Little 1966, Saatçioğlu 1976). Türkiye'deki yayılışının fazlalığı sebebiyle Türk çamı (Turkish red pine) olarak da adlandırılan kızılçam, doğu Akdeniz bölgesine özgü müşir çam türlerimizden birisidir. Kızılçam ülkemizde normal olarak 3.451.269 ha, bozuk nitelikte 2.158.946 ha olmak üzere toplamda 5.610.215 hektarlık yayılışıyla en geniş yayılış gösteren çam türümüzdür (OGM 2015). Hem yayılış alanı fazlalığı hem de ekonomik değeri büyük olan türün yaklaşık \%39'u bozuk niteliktedir. Dolayısıyla kızılçam gerek doğal yayılış bölgelerinde gerek bozuk nitelikli alanlarında gerekse de endüstriyel plantasyonlar noktasında oldukça geniş çapta ağaçlandırmalara konu bir türdür (Boydak 2006a ve 2006b). Zira, çeşitli sebeplerle orman örtüsünü kaybetmiş kızılçam sahalarının yeniden ağaçlandırılması ve bozuk vasıflı kızılçam ormanlarının ıslahı işleri ormancılığımızın önemli sorunları arasında değerlendirilmektedir. Bu nedenle, ileriki dönemlerde kızılçamda daha fazla miktar ve kalitede fidana ihtiyaç duyulacaktır.

Çalışmada, Burdur-Gölhisar orman fidanlığında daha kaliteli kızılçam fidanları yetiştirilebilmesi için farklı orijinli 1+0 yaşı fidanların aynı yetişme ortamında morfolojik özellikler bakımından karşılaştırması yapılmaya çalışılmıştır. Çalışma sonuçlarıyla, türün fidanlık tekniği, verimsiz ormanlarının ıslahı ve ülkemizdeki ağaçlandırma çalışmalarına da katkı sağlanması amaçlanmıştır.

\section{MATERYAL VE YÖNTEM}

\section{Materyal}

Çalışma, Burdur-Gölhisar Orman Fidanlık Şefliği'nde gerçekleştirilmiştir. Çalışmaya konu fidanlığın coğrafik, iklim, toprak ve sulama suyu bilgileri Çizelge 1 'de verilmiştir.

Çizelge 1. Gölhisar Orman Fidanlık Şefliği Verileri

\begin{tabular}{|c|c|}
\hline \multicolumn{2}{|l|}{ Coğrafik Özellikler } \\
\hline ilii & Burdur \\
\hline i̇lçesi & Gölhisar \\
\hline \multirow[t]{2}{*}{ Bağlı olduğu birim } & Eğirdir Orman Fidanlık \\
\hline & Müdürlüğü \\
\hline Enlem & 3709'32" Kuzey \\
\hline Boylam & $29^{\circ} 28^{\prime} 27^{\prime \prime}$ Doğu \\
\hline Rakım (m) & 1380 \\
\hline Genel Bakı & Doğu \\
\hline \multicolumn{2}{|l|}{ İklim Özellikleri } \\
\hline Yıllık ortalama sıcaklık $\left({ }^{\circ} \mathrm{C}\right)$ & 14.4 \\
\hline Yıllık maksimum sıcaklık ort. $\left({ }^{\circ} \mathrm{C}\right)$ & 19.4 \\
\hline Yıllık minimum sıcaklık ort. $\left({ }^{\circ} \mathrm{C}\right)$ & 9.4 \\
\hline Yıllık maksimum sıcaklık $\left({ }^{\circ} \mathrm{C}\right)$ & 31.0 \\
\hline Yıllık minimum sıcaklık $\left({ }^{\circ} \mathrm{C}\right)$ & 2.0 \\
\hline Yıllık Ortalama Yağış (mm) & 618.0 \\
\hline \multicolumn{2}{|c|}{ Toprak Özellikleri (5 numaralı parsel) } \\
\hline Derinlik $(\mathrm{cm})$ & $0-30$ \\
\hline Kum (\%) & 27.21 \\
\hline Toz (\%) & 23.98 \\
\hline Kil (\%) & 48.61 \\
\hline Toprak türü & Kil \\
\hline $\mathrm{pH}$ & 8.06 (Orta alkali sınıfı) \\
\hline Total kireç (\%) & 9.95 (Yüksek seviyede) \\
\hline Total azot (\%) & 0.10 (Düşük seviye) \\
\hline Tuzluluk (mS/cm) & 0.219 (Az tuzlu sınıfı) \\
\hline Organik madde (\%) & 1.99 (Az seviye) \\
\hline Sodyum (ppm) & 513 (Çok yüksek) \\
\hline Kalsiyum (ppm) & 6237 (Çok yüksek) \\
\hline Potasyum (ppm) & 380 (Yüksek seviye) \\
\hline Magnezyum (ppm) & 752 (Yüksek seviye) \\
\hline Fosfor (ppm) & 14 (Yeterli seviye) \\
\hline \multicolumn{2}{|l|}{ Sulama Suyu Özellikleri } \\
\hline Elektrik Geçirgenlik & 0.416 \\
\hline \multicolumn{2}{|l|}{ (mikromhos/cm) } \\
\hline Sodyum yüzdesi (\%Na) & 5.00 \\
\hline Sodyum adsorpsiyon oranı (SAR) & 0.16 \\
\hline $\mathrm{pH}$ & 8.10 \\
\hline Sulama suyu sınıfı & (C2-S1) Orta tuzlu-Az sodyumlu \\
\hline
\end{tabular}


Çalışma kapsamında, Gölhisar (Evciler-Koçaş) orijinli (37 04' 30" Kuzey enlemi - 29³2' 40" Doğu boylamı. Yükselti: $1100 \mathrm{~m}$.) Antalya'da tesis edilen ( $36^{\circ} 58^{\prime} 11^{\prime \prime}$ Kuzey enlemi - 30 32' 42" Doğu boylamı. Yükselti: $260 \mathrm{~m}$ ) Düzlerçamı Tohum Bahçesi (TB8)(P1) ve Bucak (Uludere) orijinli (37 $30^{\prime} 41^{\prime \prime}$ Kuzey enlemi - 30 40'51" Doğu boylamı. Yükselti: 800 m.) Antalya'da tesis edilen ( $36^{\circ} 58^{\prime} 19^{\prime \prime}$ Kuzey enlemi ile $30^{\circ} 39^{\prime} 52^{\prime \prime}$ Doğu boylamı 275 metre yükseltili)
Döşemealtı Tohum bahçesi (TB19)(P2) orijinli kızılçam fidanları 2020 yılı vejetasyon dönemi sonunda örneklenmiştir (Şekil 1). Genellikle kızılçam türünde ağaçlandırmalarda 1+0 yaşlı fidanlar kullanıldığı için çalışmada $1+0$ yaşlı fidanlar üzerinde durulmuştur (Özel ve ark. 2018). Her popülasyondan 50'şer birey örneklenerek gerçekleştirilen çalışmada, kızılçam tohumları $37.5 \mathrm{~g} / \mathrm{m}^{2}$ sıklık ile ekilmiştir (Şekil 1)
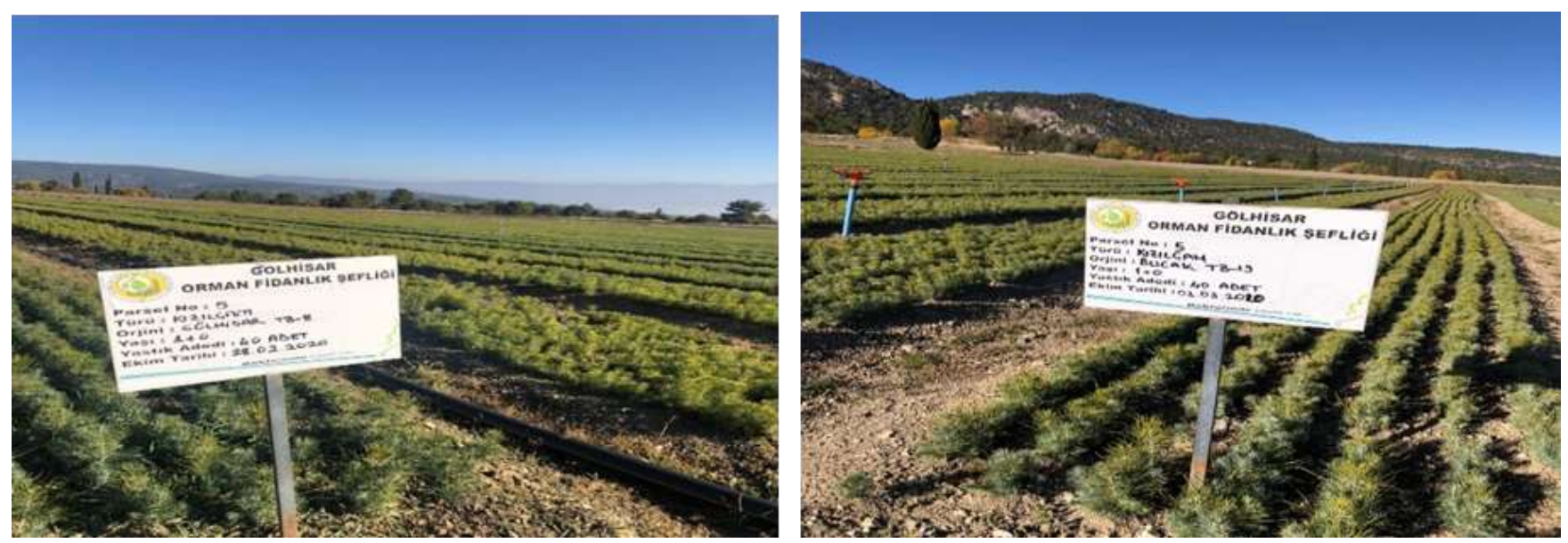

Şekil 1. Çalışmaya konu (TB8)(P1) ve (TB19)(P2) orijinli kızılçam fidanlarından görüntüle

\section{Yöntem}

\section{Morfolojik Özellikler}

Fidanlarda morfolojik özellikler olarak, kök boğazı çapı (KBÇ, $0.1 \mathrm{~mm}$ duyarlılıkla), fidan boyu (FB, $0.1 \mathrm{~cm}$ duyarlılıkla), $1 \mathrm{~cm}$ 'den uzun yan dal sayısı (DS), $1 \mathrm{~cm}$ 'den uzun ibre sayısı (IS), $1 \mathrm{~cm}$ 'den uzun kök sayısı (KS), en uzun kök uzunluğu (EUK, $0.1 \mathrm{~cm}$ duyarlılıkla) ve tomurcuk sayısı (TS) ölçümleri yapılmıştır (Şekil 2).
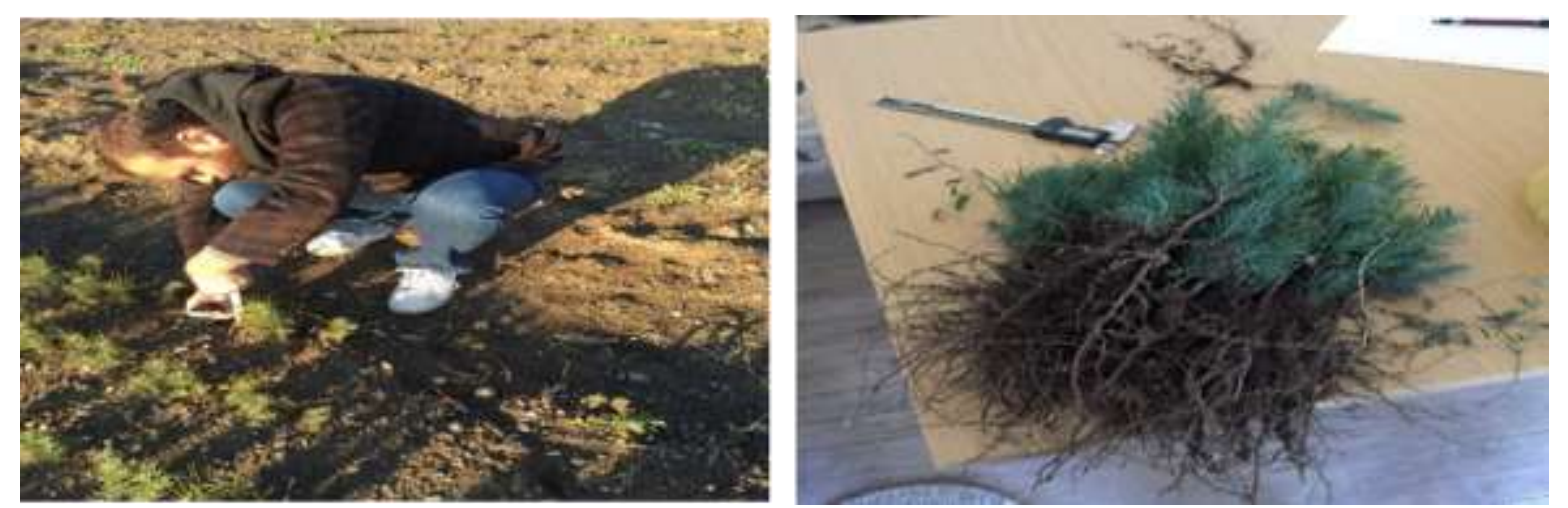

Şekil 2. Örneklenen fidanlarda ölçümler

Elde edilen ölçümler yardımıyla, gürbüzlük indisi (Gi) aşağıdaki eşitlik (1) yardımıyla hesaplanmıştır (Aphalo ve Rikala 2003, Gülseven ve ark. 2019).

$$
G \dot{I}=\frac{\text { Fidan Boyu }(\mathrm{mm})}{\text { Kök Boğazı Çapı }(\mathrm{mm})}
$$

\section{İstatistiksel Analizler}

Elde edilen veriler SPSS paket programında değerlendirilerek (Özdamar 1999); temel istatistiksel değerler yanında, çalışmaya konu özellikler bakımından popülasyon içi ve popülasyonlar arası karşılaştırmalar için 
basit varyans analizi uygulanmıştır. Özellikler arası ilişki ve etkileşimin belirlenmesinde, Pearson korelasyon analizi ve regresyon analizinden faydalanılmıştır.

\section{Fidan Kalitesi}

Fidanların tohum kaynaklarına göre, boy ve kök boğazı çapı bakımından Türk Standartları Enstitüsü'nün (TSE) kalite sınıflarına dağılımı belirlenmiştir (Çizelge 2) (Anonim 1988).

Çizelge 2. TSE'ye göre (TS/2265) fidan boyu ve kök boğazı çapı için 1+0 yaşlı kızılçam fidan kalite sınıfları

\begin{tabular}{cccc}
\hline $\begin{array}{c}\text { Kalite } \\
\text { Sınıfı }\end{array}$ & $\begin{array}{c}\text { Fidan Boyu } \\
(\mathbf{F B}, \mathbf{c m})\end{array}$ & $\begin{array}{c}\text { Kök Boğazı Çapı } \\
\text { (KBÇ, } \mathbf{m m})\end{array}$ & FB+KBÇ \\
\hline I. Sınıf & $12 \leq$ & $2 \leq$ & $12 \leq \mathrm{FB}+2 \leq \mathrm{KBC}$ \\
II. Sınıf & $12>\mathrm{FB} \geq 10$ & - & $12>\mathrm{FB} \geq 10+2$ \\
Elverişsiz & $10>$ & $2>\mathrm{KBC}$ \\
\hline
\end{tabular}

\section{BULGULAR VE TARTIŞMA}

\section{Morfolojik Özelliklere Ait Bulgular ve Tartışma}

Fidanlarda yapılmış olan KBÇ, FB, DS, is, EUK, KS, TS morfolojik özelliklerine ait tanımlayıcı istatistiksel veriler
Çizelge 3'te verilmiştir. Örneğin, P1 popülasyonunda ortalama fidan boyu ve kök boğazı çapı sırasıyla $13.23 \mathrm{~cm}$ ve $3.15 \mathrm{~mm}$ olarak bulunmuştur (Çizelge 3). P2 popülasyonunda ortalama fidan boyu ve kök boğazı çapı sırasıyla 13.44 ve 3.29 olarak bulunmuştur (Çizelge 3). P1 ve $\mathrm{P} 2$ popülasyonları ortalama fidan boyu ve ortalama kök boğazı çapı bakımından benzerlik göstermiştir. Ayrıca, Çizelge 3'ten görüleceği üzere ölçülen birçok morfolojik özellik bakımından popülasyon içi minimum ve maksimum değerler arasındaki değiş̧im aralığının yüksek olması, popülasyonlar içerisinde yüksek bir varyasyonun olduğunu göstermektedir. Zira, P1 popülasyonundaki grup içi minimum ve maksimum değerler arasındaki yaklaşık olarak değişim oranları; KBÇ için 4 kat, FB için 4 kat, DS için 6 kat, is için 9 kat, EUK için 5 kat, KS için 3 kat, TS için 10 kat, Gi için 3 kat olarak görülmektedir. P2 popülasyonundaki grup içi minimum ve maksimum değerler arasındaki yaklaşık olarak değişim oranları ise, KBÇ için 6 kat, FB için 3 kat, DS için 6 kat, is için 7 kat, EUK için 1.5 kat, KS için 2.5 kat, TS için 8 kat, Gi için 5 kattır. Bu durum, fidan seçiminde bireysel seleksiyonun önemini açıkça göstermektedir.

Çizelge 3. Morfolojik özelliklere ait tanımlayıcı istatistiksel veriler

\begin{tabular}{|c|c|c|c|c|c|c|c|c|c|}
\hline \multirow{2}{*}{ Özellikler } & \multicolumn{3}{|c|}{ P1 } & \multicolumn{3}{|c|}{ P2 } & \multicolumn{3}{|c|}{ Genel } \\
\hline & Ort. & Min. & Mak. & Ort. & Min. & Mak. & Ort. & Min. & Mak. \\
\hline KBÇ (mm) & 3.15 & 1.42 & 5.02 & 3.29 & 2.15 & 13.11 & 3.22 & 1.42 & 13.11 \\
\hline FB $(\mathrm{cm})$ & 13.23 & 6.27 & 25.11 & 13.44 & 6.27 & 18.2 & 13.33 & 6.27 & 25.11 \\
\hline DS & 5.88 & 2 & 12 & 6.52 & 2 & 12 & 6.2 & 2 & 12 \\
\hline is & 757.8 & 180 & 1777 & 873.2 & 272 & 1680 & 815.5 & 180 & 1777 \\
\hline EUK $(\mathrm{cm})$ & 28.77 & 8 & 46 & 30.65 & 24.36 & 41.41 & 29.71 & 8 & 46 \\
\hline KS & 10.94 & 6 & 18 & 16.62 & 10 & 24 & 13.78 & 6 & 24 \\
\hline TS & 2.16 & 0 & 10 & 0.72 & 0 & 8 & 1.44 & 0 & 10 \\
\hline Gi & 42.22 & 22.84 & 67.95 & 43.23 & 11.70 & 59.39 & 42.73 & 11.70 & 67.95 \\
\hline
\end{tabular}

Uygulanan basit varyans analizi sonuçlarına göre orijinler arasında en uzun kök uzunluğu ve tomurcuk sayısı bakımından anlamlı $(p<0.05)$ farklılıklar olduğu tespit edilmiştir. Çalışma sonucumuza paralel olarak, Uslu ve Bilir (2020) dallı servi ve piramit servide taksonlar arası, Çetinkaya ve Bilir (2019) fidan tipleri arası istatistiksel bakımdan anlamlı $(p<0.05)$ fark belirlemişlerdir. Gülcü ve Gültekin (2005) de farklı orijinli boylu ardıç popülasyonları arasında anlamlı fark olduğunu belirtmişlerdir. Yine kızılçamın Antalya Orman Fidanlı̆̆ında yetiştirilen fidanları üzerinde gerçekleştirilen çalışmada, türün 1+0 yaşlı çıplak köklü ve $1+1$ yaşlı tüplü fidanlarında ortalama fidan boyu sırasıyla $8.2 \mathrm{~cm}$ ve $16.5 \mathrm{~cm}$, kök boğazı çapı ise $3.97 \mathrm{~mm}$ ve $5.84 \mathrm{~mm}$ olarak bulunmuştur (Bilir 2019). Bu sonuçlar türün morfolojik özellikleri üzerinde birçok çevresel ve biyolojik faktörün önemli olduğunu göstermektedir. Fidan boyu ve kök boğazı çapı hem yaşama yüzdesi hem de dikimden sonraki süreçte fidan gelişimi üzerinde önemli bir etkiye sahiptir (Gülcü ve Uysal 2010). Değişik orman ağacı türlerinde 
gerçekleştirilen çalışmalarda da boylu ve kalın çaplı fidanların ağaçlandırma çalışmalarında yaşama yüzdesi ve gelişim bakımından diğerlerine göre üstünlük gösterdiği belirlenmiştir (Bacon 1979, Rose ve ark. 1990, Yahyaoğlu ve Genç 2007, Gülcü ve Uysal 2010).

\section{Morfolojik Özellikler Arasındaki ilişkiler Ve Fidan Kalitesi}

Uygulanan Pearson korelasyon analizi sonucunda popülasyonlarda morfolojik özellikler bakımından genel olarak anlamlı $(p \leq 0.05)$ pozitif ilişkiler belirlenmiştir (Çizelge 4).

Çizelge 4. Pearson korelasyon analizi sonuçları

\begin{tabular}{lllllll}
\hline & KBÇ & FB & DS & is & EUK & KS \\
\hline FB & $0.414^{* *}$ & & & & & \\
DS & $0.353^{* *}$ & $0.409^{* *}$ & & & & \\
iS & $0.417^{* *}$ & $0.389^{* *}$ & $0.503^{* *}$ & & & \\
EUK & $0.176^{\text {ns }}$ & $0.467^{* *}$ & $0.309^{* *}$ & $0.428^{* *}$ & & \\
KS & $0.215^{*}$ & $0.326^{* *}$ & $0.332^{* *}$ & $0.438^{* *}$ & $0.333^{* *}$ & \\
TS & $0.273^{* *}$ & $0.183^{\text {ns }}$ & $0.177^{\text {ns }}$ & $0.170^{\text {ns }}$ & $0.095^{\text {ns }}$ & $-0.111^{\text {ns }}$
\end{tabular}

* ilişkiler \%95 önem düzeyinde anlamlıdır, ** ilişkiler \%99 önem düzeyinde anlamlıdır, ns ilişkiler anlamsızdır.

Benzer sonuçlar Bilir ve Çetinkaya (2018) tarafından türün tohum bahçesi orijinli 1+0 yaşlı fidanlarında da boy ve kök boğazı çapı arasında belirlenmiştir. Farklı orman ağacı türlerinde yapılan çalışmalarda da fidan morfolojik özellikleri arasında anlamlı $(p<0.05)$ pozitif ilişkiler belirlenmiştir (Eyüboğlu ve Karadeniz 1987, Morris ve ark. 1990, Dilaver 2015).

Fidan kalite sınıflamasında kullanılan kriterlerden birisi olan gürbüzlük indisi fidan boyunun kök boğazı çapına oranını ifade eder (Aphalo ve Rikala 2003, Gülseven ve ark. 2019). Bu değerin küçük olması fidanların kalitesi açısından arzu edilen bir özellik olup, düşük gürbüzlük indisine sahip fidanlar dikim ve taşıma zararlarından daha az etkilenmekte ve dikim başarısı daha yüksek olmaktadır (Genç 1992). Gürbüzlük indisi sınıflamasına göre gürbüzlük indisi değeri 50'nin altında olan fidanlar iyi fidan, 50 - 60 arası olan fidanlar orta fidan ve 60 üstünde olan fidanlar ise kötü fidan olarak kabul edilmektedir (Yahyaoğlu ve Genç 2007). Türk Standartları Enstitüsü (TSE) açısından da fidan kalitesi noktasında fidan boyu ve kök boğazı çapı kriterleri dikkate alınmaktadır. Dolayısıyla fidan boyu ve kök boğazı çapı özellikleri kullanılarak hesaplanan gürbüzlük indisi üzerinde değişkenlerin ne ölçüde etkili olduğunu belirleyebilmek için aşamalı çoklu regresyon analizi uygulanmıştır (Çizelge 5).

Çizelge 5. Gürbüzlük indisi bağlamında aşamalı çoklu regresyon analizi sonuçları

\begin{tabular}{llcccc}
\hline Model & Değişkenler & $\begin{array}{c}\text { Model } \\
\text { Katsayıları }\end{array}$ & $\mathbf{R}^{\mathbf{2}}$ & $\begin{array}{c}\text { Önem } \\
\text { Düzeyi }\end{array}$ & $\mathbf{F}$ \\
\hline $\mathbf{1}$ & Sabite & 33.999 & 0.047 & 0.000 & 4.841 \\
& EUK & 0.296 & & & \\
$\mathbf{2}$ & Sabite & 34.281 & & & \\
& EUK & 0.326 & 0.101 & 0.000 & 5.459 \\
& TS & -0.819 & & & \\
\hline
\end{tabular}

Bağımlı Değişken: Gürbüzlük İndisi

Çoklu regresyon analizi sonucunda, en anlamlı ilişkileri veren (R2 değerleri en yüksek) 2 farklı model ortaya çıkmıştır. En anlamlı ilişki en yüksek R2 değerine sahip olan ikinci modeldir. En yüksek açıklama düzeyine sahip olan ikinci model içerisinde sırasıyla en uzun kökün uzunluğu (EUK) ve tomurcuk sayısı (TS) değişkenleri yer almıştır. Yani gürbüzlük indisi açısından en önemli değişkenler sırasıyla en uzun kökün uzunluğu ve tomurcuk sayısı olmuştur (Çizelge 5). Demircioğlu ve ark. (2004) Kastamonu-Taşköprü orman fidanlığında $2+0$ yaşlı sarıçam (Pinus sylvestris L.) fidanlarında yapmış oldukları çalışmada gürbüzlük indisini 40.14 olarak bulmuşlardır. Ayan ve ark. (2020) Samsun-Gelemen Orman Fidanlığı koşullarında yetiştirilen $2+0$ ve $3+0$ yaşlı tüplü Fıstıkçamı (Pinus pinea L.) fidanlarında gürbüzlük indisini 49.01 ve 56.44 belirlemişlerdir. Aksu ve Tilki (2013) ise Quercus pontica üzerine yaptıkları çalışmada, fidan boy/çap değerleri (gürbüzlük indisi) üzerinde orijinin ve tohum büyüklüğünün etkili olmadığını belirtmişlerdir.

TSE'nin yürürlükte olan kalite sınıflarına (Anonim 1988) göre; P1 popülasyonunda fidanların $\% 56$ 'sı 1 . sınıf, $\% 22$ 'si 2. sınıf, \%22'si dikime elverişsizdir. P2 popülasyonunda ise fidanların $\% 84^{\prime}$ ü 1. sınıf, $\% 10^{\prime}$ u 2 . sınıf, $\% 6^{\prime}$ sı dikime elverişsiz yani ıskarta sınıfındadır (Çizelge 6). Tüm fidanlar TSE kalite sınıfları bağlamında değerlendirildiğinde ise \%70'i 1. sınıf, \%16'sı 2. sınıf, \%14'ü dikime elverişsizdir (Çizelge 6). P2 popülasyonunda kaliteli fidanlar daha yüksek oranda bulunmuştur (Çizelge 6). Bilir (1997) tarafından 2+0 yaşı çıplak köklü Toros sediri fidanları üzerinde gerçekleştirilen çalışmada TSE 'ye göre fidanların 
boy bakımından $\% 75$ 'i 1 . sınıf, \%12'si 2. sınıf, \%11'i 3 . sınıfta, \%3'ünün dikime elverişsiz fidan sınıfında yer aldığı belirtilmiştir. Toros sedirinde tohum bahçesi orijinli $1+0$ yaşlı tüplü ve çıplak köklü fidanlarında yapılan çalışmada da çıplak köklü fidanların boy bakımından \%12'sinin, kök boğazı çapı bakımından ise \%41'inin dikime elverişsiz olduğu ve bu değerlerin tüplü fidanlar için sırasıyla \%7 ve \%9 olduğu belirtilmiştir (Bilir ve Çetinkaya 2018). Kızılçam üzerinde gerçekleştirilen başka bir çalışmada ise fidanların Türk Standartları Enstitüsü'nün boy ve kök boğazı çapı kalite sınıflarına göre dağıımlarının belirlenmesi sonucunda, en kaliteli fidanların tohum bahçesinden elde edilen tüplü fidanlarda olduğu görülmüştür (Dilaver 2015).

Çizelge 6. Örneklenen fidanların TSE'ye göre kalite sınıflarına dağılımı

\begin{tabular}{lccc}
\hline Orijinler & 1. Sınıf & 2. Sınıf & Elverişsiz \\
\hline Gölhisar (Evciler-Koçaş) & $\% 56$ & $\% 22$ & $\% 22$ \\
Bucak (Uludere) & $\% 84$ & $\% 10$ & $\% 6$ \\
\hline Genel & $\% 70$ & $\% 16$ & $\% 14$ \\
\hline
\end{tabular}

\section{SONUÇ VE ÖNERILER}

Fidanlık çalışmalarında hedef, mümkün olduğunca fazla miktarda, sağlıklı, dikime elverişli ve kaliteli fidanlar üretmektir. Dolayısıyla fidanlıklarda uygun tohum kaynaklarının belirlenmesi fidan kalitesi açısından önemli aşamalardan biridir. Ülkemizde fidanlar için kalite sınıflarının belirlenmesinde kullanılan kriterler genel olarak fidan boyu ve kök boğazı çapıdır. Dünya ülkelerinde kalite kriterleri olarak fidan boyu, kök boğazı çapı, gövde ve kök taze ve kuru ağılıkları, gövde/kök kuru ağırlık oranları gibi morfolojik özellikler kullanılmaktadır. Bu çalışmada, orijinlerin fidan boyu, kök boğazı çapı, kök uzunluğu, yan dal, tomurcuk, kök ve ibre sayıları gibi bazı fidan morfolojik özellikleri üzerine etkileri belirlenmiştir.

Yapılan istatistiksel değerlendirmeler sonucu fidanlarda gerek popülasyon içi gerekse de popülasyonlar arası anlamlı $(p<0.05)$ farklılıklar bulunmuştur. Bu durum ağaçlandırma çalışmalarında kullanılacak fidanların seçiminde bireysel seçimin önemini açıkça göstermektedir. Popülasyonlar fidan boyu ve kök boğazı çapı kriterleri bakımından benzerlik gösterirken, orijinler arasında kök ve tomurcuk sayısı bakımından anlamlı $(p<0.05)$ farklııklar olduğu tespit edilmiştir. Bu sonuç, fidan kalitesinde kullanılacak kalite kriterlerinin önemini açıkça göstermektedir. Fakat bu sonuç, fidanların dikimden sonraki arazi performansı ile birlikte değerlendirilerek daha sağlıklı sonuçlar alınabilir. Uygulanan korelasyon analizi sonucunda ise popülasyonlarda morfolojik özellikler bakımından genel olarak anlamlı $(p \leq 0.05)$ pozitif ilişkiler belirlenmiştir. Ancak, en uzun kökün uzunluğu ve kök boğazı çapı arasında anlamlı $(p<0.05)$ doğrusal bir ilişki bulunamamıştır. Tomurcuk sayısı ile sadece kök boğazı çapı arasında anlamlı doğrusal bir ilişki bulunmuştur. Regresyon analizi sonucunda ise, fidanlarda taşıma zararları ve ağaçlandırma başarısı açısından önemli bir kriter olan gürbüzlük indisi bağlamında en etkili olan faktörler en uzun kökün uzunluğu ve tomurcuk sayısı olarak bulunmuştur. Bu durum fidan morfolojik özelliklerinin kalite kriterleri üzerindeki etkisini açıç̧a göstermektedir.

Gölhisar Orman Fidanlık Şefliği için tohum kaynağı olarak, Bucak (Uludere) orijinli Döşemealtı Tohum bahçesi (TB19) daha uygun olacaktır. Çünkü çalışmamız sonucunda ağaçlandırmalar açısından önemli etkenlerden birisi olarak görülen morfolojik özellikler bu tohum bahçesi için daha yüksek bulunmuştur. Ayrıca Bucak (Uludere) orijinli fidanlar gerek TSE kalite sınıfları gerekse de gürbüzlük indisi bağlamında da daha makul sonuçlar vermiştir.

\section{TEŞEKKÜR}

Çalışmamızdaki yardım ve katkılarından dolayı Gölhisar Orman Fidanlık Şefliği çalışanları ve Orm. Yük. Müh. Şule ÖZDAĞ’a teşekkür ederiz.

\section{KAYNAKLAR}

Aksu Y, Tilki F (2015) Orijin ve tohum büyüklüğünün Quercus pontica fidanlarının yaşama yüzdesi ve morfolojik özellikleri üzerine etkisi. Artvin Çoruh Üniversitesi Orman Fakültesi Dergisi 16(2): 216-226

Anonim (1988) İ̆ne Yapraklı Ağaç Fidanları, TS 2265/Şubat-1988. Türk Standartları Enstitüsü yayınları, Ankara

Aphalo P, Rikala R (2003) Field performance of silver-birch plantingstock grown at different spacing and in containers of different volume. New Forests, 25(2) 93-108

Ayan S, Civek E, Yer Çelik EN, Gülseven O, Özel HB, Eshaibi JAH, Akın SŞ, Yılmaz E (2020) Farklı yaşlardaki tüplü Fıstıkçamı (Pinus pinea L.) fidanlarının morfolojik kalite özellikleri. Bartın Orman Fakültesi Dergisi 22(2):633-641

Bacon GJ (1979) Seedling morphology as an indicator of planting stock quality in conifers. Unpublished manuscript presented at 
Workshop on 'Techniques for evaluating planting stock quality' New Zealand

Bilir N (1997) Doğu Karadeniz Bölgesi'nde Toros Sediri (Cedrus libani A.Rich.) Orijin Denemeleri Fidanlık Aşaması. Karadeniz Teknik üniversitesi, Fen Bilimleri Enstitüsü, Yüksek Lisans Tezi, Trabzon, 90 $\mathrm{S}$

Bilir N, Kaya C, Uusan M D (2010) Aydın orijinli fıstıkçamı (Pinus pinea L.) fidanlarında morfolojik özellikler ve fidan kalitesi. Kastamonu Üniversitesi Orman Fakültesi Dergisi 10(1) 37-43

Bilir N, Çetinkaya D (2018) Variation of Morphology and Quality in 1+0 Year Containerized and Bare-Root Seedlings of Taurus Cedar (Cedrus libani A. Rich.). 4th International Conference Reforestation Challenges, p. 10, 19-23 June, Belgrade, Serbia

Bilir N (2019) Kızılçam'da (Pinus brutia Ten.) Fidan Kalitesi. Mehmet Akif Ersoy Üniversitesi Fen Bilimleri Enstitüsü Dergisi 10(1) 95-101

Boydak M, Dirik H, Çalıkoğlu M (2006)a Kızılçamın (Pinus brutia Ten.) Biyolojisi ve Silvikültürü. OGEM-Vakfı Yayınları, Ankara, $364 \mathrm{~s}$

Boydak M, Dirik H, Çalıkoğlu M (2006)b Biology and Silviculture of Turkish Red Pine (Pinus brutia Ten.). Ormancılığı Geliştirme ve Orman Yangınları ile Mücadele Hizmetlerini Destekleme Vakfı, Ankara $253 \mathrm{~s}$

Critchfield WB, Little EL (1966) Geografic distribution of the pines of the world. U.S.D.A. Forest Service Misc. Publ

Çetinkaya D, Bilir N (2019) Toros sediri'nde (Cedrus libani A. Rich.) fidan tipi $x$ fidan morfolojisi etkileşimi. Mehmet Akif Ersoy Üniversitesi Fen Bilimleri Enstitüsü Dergisi 10(1) 28-33

Davis BH (1965) Flora of Turkey. 9 Volumes and Suplementum At the Unversity Pres, Edinburgh

Demircioğlu N, Ayan S, Avanoğlu B, Sıvacıoğlu A (2004) KastamonuTaşköprü Orman Fidanlığında üretilen $2+0$ yaşlı Sarıçam (Pinus sylvestris L.) Fidanlarının TSE Normlarına göre değerlendirilmesi. Pamukkale Üniversitesi Mühendislik Bilimleri Dergisi 10(2) 243251

Dilaver M (2015) Balıkesir-Dursunbey Orman Fidanlığında Üretilen Tohum Meşceresi ve Tohum Bahçesi Orijinli Kızılçam (Pinus brutia Ten.) Fidanlarında Morfolojik Özellikler. Süleyman Demirel Üniversitesi, Fen Bilimleri Enstitüsü, Yüksek Lisans Tezi, Isparta, 33 $s$

Eyüboğlu AK, Karadeniz A (1987) Doğu Kayınında (Fagus orientalis Lipsky.) Dikim Anındaki Fidan Boyu ve Çapı İle Üç Yıllık Boy Büyümesi Arasındaki illişkiler. Ormancılık Araştırma Enstitüsü Teknik Bülten Serisi 185:5-13 Ankara

Genç M (1992) Doğu Ladini (Picea orientalis (L.) Link) Fidanlarına Ait Bazı Morfolojik ve Fizyolojik Özelliklerle Dikim Başarısı Arasındaki İlişkiler. KTÜ, Fen Bilimleri Enstitüsü, Doktora tezi, Trabzon, 272 s
Gülcü S, Gültekin HC (2005) Göller yöresi boylu Ardıç (Juniperus excelsa Bieb.) orijinlerinin morfolojik fidan kalite kriterleri bakımından karşılaştırılması. Kafkas Üniversitesi Artvin Orman Fakültesi Dergisi 6 1-2 121-127

Gülcü S, Uysal SÇ (2010) Kuş iğdesi'nde (Elaeagnus angustifolia L.) Yetiştirme Sıklığının Fidan Morfolojik Özelliklerine Etkisi. Türkiye Ormancilık Dergisi 11(2) 74-81

Gülseven O, Ayan S, Özel HB, Yer EN (2019) Farklı doğu kayını (Fagus orientalis Lipsky.) populasyonlarına ait fidanların morfolojik ve fizyolojik karakteristikleri. Türkiye Ormancllık Dergisi 20(3) 180186

Morris DM, Macdonald GB, Mcclain KM (1990) Evaluation Of Morphological Attributes As Response Variables to Perennial Competition For 4 Years Old Black Spruce And Jack Pine Seedlings. Canadian Journal of Forest Research 20 (11): 1696-1703

OGM (2015) Türkiye Orman Varlığı 2015. Ankara: T.C. Orman ve Su İşleri Bakanlığı Orman Genel Müdürlüğü Yayını 36s

Özdamar K (1999) Paket Programlar ile İstatistiksel Veri Analizi. Kaan Kitabevi, Eskişehir

Özel HB, Yücedağ C, Bilir N, Ölmez Z, Aydınhan V (2018) Kızılçamda (Pinus brutia Ten.) Fidan Tiplerinin Morfolojik Karakterlere Etkisi. Bartın Üniversitesi Uluslararası Fen Bilimleri Dergisi 1(1) 43-47

Rose R, Campbell SJ, Landis TD (1990) The target seedling concept. In: Proceedings of Combined Meeting of the Western Forest Nursery Associations, Roseburg, 13-17 August, Oregon. USDA Forest Service, Gen. Tech. Rep. RM-200, Rocky Mountain Forest and Range Experiment Station, Colorado, pp. 1-8

Saatçioğlu $F$ (1976) Silvikültürün biyolojik esasları ve prensipleri (Silvikültür I). İstanbul Üniversitesi, Orman Fakültesi Yayını, 2187: 222, İstanbul

Selik M (1963) Kızılçam (Pinus brutia Ten.)'ın botanik özellikleri üzerinde arastırmalar ve bunların Halepçamı (Pinus halepensis Mil.) vasıfları ile mukayesesi. Orman Genel Müdürlüğü Yayını $353 / 3688 \mathrm{~s}$

Şevik H, Topaçoğlu O, Umur R, Çiftçioğlu S (2013) Uludağ Göknarı (Abies nordmanniana subsp. bornmülleriana mattf.)'nda 2+ 1 Yaşlı Fidan Morfolojik Özellikleri Bakımından Populasyonlar Arası Farklılıklar. Karadeniz Fen Bilimleri Dergisi 3(9) 91-102

Toker MC (2004) Bitki morfolojisi. Ankara Üniversitesi, Fen Fakültesi, Biyoloji bölümü, $131 \mathrm{~s}$, Ankara

Uslu M, Bilir N (2020) Dallı Servi ve Piramit Servi'nin Morfolojik Fidan Özellikleri. Mehmet Akif Ersoy Üniversitesi Fen Bilimleri Enstitüsü Dergisi 11 (1) 12-21

Yahyaoğlu Z, Genç M (2007) Fidan Standardizasyonu, Standart Fidan Yetiştirmenin Biyolojik ve Teknik Esasları. SDÜ Orman Fakültesi Yayın No: 75, Isparta 